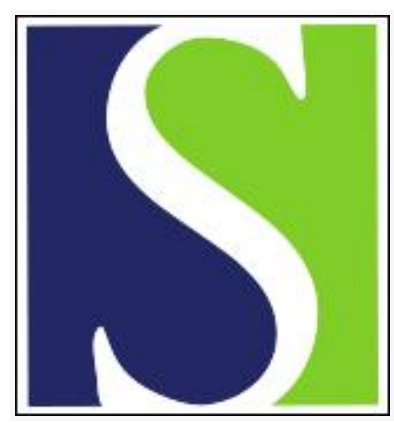

Scand J Work Environ Health 2011;37(3):204-212

https://doi.org/10.5271/sjweh.3137

Published online: 30 Nov 2010, Issue date: May 2011

Workplace bullying and subsequent sleep problems - the Helsinki Health Study

by Lallukka T, Rahkonen O, Lahelma E

Affiliation: Hjelt Institute, Department of Public Health, FIN-00014 University of Helsinki, Finland. tea.lallukka@helsinki.fi

Refers to the following text of the Journal: 2001;27(1):63-69

The following articles refer to this text: 2012;38(1):38-46;

2013;39(6):535-549; 2016;42(1):26-33; 2016;42(5):359-370

Key terms: follow-up study; health; insomnia; obesity; sleep problem; sociodemographic factor; the Helsinki Health Study; work environment; workplace bullying

This article in PubMed: www.ncbi.nlm.nih.gov/pubmed/21116599 


\title{
Workplace bullying and subsequent sleep problems - the Helsinki Health Study
}

\author{
by Tea Lallukka, PhD, ${ }^{1}$ Ossi Rahkonen, PhD, ${ }^{1}$ Eero Lahelma, PhD ${ }^{1}$
}

\begin{abstract}
Lallukka T, Rahkonen 0, Lahelma E. Workplace bullying and subsequent sleep problems - the Helsinki Health Study. Scand J Work Environ Health. 2011;37(3):204-212. doi:10.5271/sjweh.3137

Objective The associations between workplace bullying and subsequent sleep problems are poorly understood. This study aims to address this evidence gap.

Methods We used the Helsinki Health Study questionnaire survey data at baseline in 2000-2002 and follow-up in 2007 (N=7332). The 4-item Jenkins sleep questionnaire was used in both surveys. Two measures of workplace bullying asked whether the respondent had (i) reported being bullied and (ii) observed bullying. Logistic regression models were fitted, adjusting for age, childhood bullying, education, working conditions, obesity, common mental disorders, limiting long-standing illness, and baseline sleep problems.
\end{abstract}

Results At baseline, 5\% of women and men reported being currently bullied. Additionally, $9 \%$ of women and $7 \%$ of men had frequently observed bullying at their workplace. Adjusted for age, reporting bullying was associated with sleep problems at follow-up among women [odds ratio (OR) 1.69, 95\% confidence interval (95\% CI) 1.30-2.20] and men (OR 3.17, 95\% CI 1.85-5.43). Also, reporting earlier bullying was associated with sleep problems among both women (OR 1.47, 95\% CI 1.26-1.72) and men (OR 1.58, 95\% CI 1.06-2.36). Separate adjustments for covariates had some effects on the associations. After full adjustment for childhood bullying and baseline sociodemographic factors, working conditions, health, and sleep problems, the associations reduced. Similarly, adjusted for age, observing bullying was associated with sleep problems among women (OR 2.00, 95\% CI 1.61-2.48) and men (OR $2.04,95 \%$ CI $1.23-3.39$ ).

Conclusions Workplace bullying is associated with sleep problems, but associations attenuate after factors related to the social environment, work, and health are simultaneously taken into account.

Key terms follow-up study; health; insomnia; obesity; sociodemographic factor; work environment.

Sleep problems are prevalent, in general, as well as among employed populations $(1,2)$ but their determinants are not well known. Physical and psychosocial working conditions are associated with sleep problems $(3,4)$, but workplace bullying has not been examined with regard to sleep problems in large-scale longitudinal studies.

Definitions about the nature of bullying vary but most of them typically capture similar phenomena. Bullying refers to situations where the victims are in an unequal position with respect to the bully (5). Such bullying also needs to be systematic and persisting. Following these lines, one of the often-used definitions of bullying reads as follows: "Bullying emerges when one or several individuals persistently over a period of time perceive themselves to be on the receiving end of negative actions from one or several persons, in situations where the target of bullying has difficulty in defending him or herself against these actions" (6). Bullying, however, may take various forms, occur in different situations and contexts, and involve both mental and physically aggressive acts $(5,7)$. Some people may also be exposed to several specific forms of insulting behavior, which cause stress and can lead to mental and physical health problems $(5,8,9)$. Bullied employees have more sickness absence (10), which further highlights the significance of the problem extending from the well-being of the bullied employees to functioning and productivity at the workplace. Bullying also affects members of work units who may not be victims of bullying themselves but mere bystanders or observers. Observing bullying reflects an adverse workplace atmosphere and can lead to similar detrimental consequences as those found among the actual victims of bullying $(9,11)$. Thus, bullying is likely to affect the employees as well as the work environment at large $(12,13)$. It can be hypothesized that observing bullying is an additional stressor

1 Hjelt Institute, Department of Public Health, University of Helsinki, Helsinki, Finland.

Correspondence to: Tea Lallukka, PhD, Hjelt Institute, Department of Public Health, PO Box 41, FIN-00014 University of Helsinki, Finland. [E-mail: tea.lallukka@helsinki.fi] 
that affects sleep, causes worry, and overall impairs the work climate. Past experiences of bullying are also potentially important and some people may have been bullied already in school. Such early experiences may have consequences later on (14), and bullying in childhood may even contribute to bullying in adulthood (15).

The prevalence of workplace bullying depends on the definition and study population. In Finland, the prevalence has varied from $5-10 \%(8,9)$. We focus on workplace bullying as one of the work-related determinants of health. Sleep problems, in turn, indicate employee health and well-being. In our framework, the work environment and employee health and well-being are the main interests. We approach these by examining workplace bullying and sleep problems. A key assumption is that bullying may cause stress and worry that contribute to sleep problems $(4,16-18)$. We also take into account childhood bullying and health-related factors to produce a better understanding about the subject.

So far, there have been sparse studies about bullying and sleep and those that have been done were either cross-sectional (11) or focused on specific occupational groups with short follow-ups and small datasets $(19,20)$. In an earlier study, sleep was examined as part of mental stress reactions to bullying (9). A recent cross-sectional study suggests that workplace bullying is associated with sleep problems among women and men (11), whereas it was unrelated to subjective poor quality of sleep in a Norwegian study among nurses after a three-month follow-up (19). Workplace bullying may, nevertheless, have long-lasting effects as even past exposures to workplace bullying have turned out to be of importance (11). In order to provide novel and firmer evidence, large scale prospective studies with longer follow-up periods and covering a variety of occupations, are needed.

The main aim of this study was to examine the consequences of workplace bullying for subsequent sleep problems. First, we aimed to examine whether those bullied at baseline were likely to report sleep problems at follow-up. Second, we aimed to examine whether those who observed such bullying were also likely to report subsequent sleep problems. Third, we aimed to examine whether the studied associations are affected by age, childhood bullying, education, working conditions, obesity, physical and mental health, or baseline sleep problems.

\section{Methods}

\section{Data}

The data were derived from the Helsinki Health Study mailed questionnaire surveys of the employees of the City of Helsinki, Finland. At baseline in 2000-2002, all participants were employed by the City of Helsinki ( $\mathrm{N}=8960$, response rate 67\%) (21). A follow-up survey was carried out among all respondents to the baseline survey in 2007 ( $\mathrm{N}=7332$, response rate 83\%). During the follow-up, $21 \%$ of the participants had retired, and $9 \%$ had changed their employer. Non-response analyses among the baseline respondents confirmed that the data were broadly representative of the target population (22, 23 ). The response rate was $69 \%$ among women and $60 \%$ among men. The adjusted prevalence ratio for 60 yearolds to respond as compared to 40 years olds was 1.07 [ $95 \%$ confidence interval $(95 \% \mathrm{CI}) 1.03-1.13$ ] among women and 1.22 (95\% CI 1.11-1.35) among men (22). As compared to managers and professionals, manual workers were somewhat less likely to respond as were those with long spells of sickness absence.

\section{Measures}

Workplace bullying was addressed by two questions similar to those used in a number of previous studies $(8,24)$. The following information was first given in the questionnaire: "Mental violence or workplace bullying means isolation of a member of the organization, underestimation of work performance, threatening, talking behind one's back, or other pressurizing". The participants were then asked whether they themselves had been bullied (responses included: "no", "earlier in this or in another job", "currently", or "could not say"). Reporting being currently bullied at baseline was defined as "reported bullying at baseline". Reporting any earlier bullying was defined as "earlier bullying". These groups, alongside those who could not say whether they were bullied or not, were compared to those who had never been bullied. A further question asked whether the participants had observed such behavior at their workplace (responses included: "not at all", "sometimes", "frequently", or "could not say").

\section{Sleep problems}

The 4-item Jenkins sleep questionnaire (25) was used both at baseline and follow-up. The respondents were asked whether they had had any of the following problems during the previous four weeks: (i) trouble falling asleep, (ii) waking up several times per night, (iii) trouble staying asleep (including waking up too early), and (iv) waking up after the usual amount of sleep feeling tired and worn out. Six response alternatives were included: (i) not at all, (ii) 1-3 days, (iii) 4-7 days (iv), 8-14 days (v), 15-21 days (vi), 22-28 days per month. The participants who responded 15-21 or 22-28 days per month to any of these items were classified as having frequent sleep problems. The others served as the reference group. Those with more than one of the four 
items missing were excluded from the analysis $(2.4 \%)$. A control analysis also excluded those reporting frequent sleep problems at baseline (data not shown). The results were similar to those received after adjustment for baseline sleep problems. We preferred retaining the whole original sample in order to avoid selection by any other covariates. The standardized Cronbach's $\alpha$ for the four items was 0.84 .

\section{Covariates}

We adjusted for age as a covariate (5-year age groups). Covariates were obtained from the baseline. Childhood bullying was measured by asking whether the participant had been bullied before he/she was 16 years old. Education was categorized into basic, intermediate, and higher education. Physical working conditions were based on a factor analysis of an 18-item inventory measuring various environmental and physical exposures at work (26). Details about these factors have been reported elsewhere $(3,27)$. Job strain was examined by a combination of job demands (9 items) and job control (9 items) (28). Four categories of the job strain model were used: (i) low job strain, (ii) passive work, (iii) active work, and (iv) high job strain (29).

Obesity was measured by body mass index of at least $30 \mathrm{~kg} / \mathrm{m}^{2}$ based on self-reported weight and height. Limiting long-standing illness was measured by any existing long-standing illness, disability, or infirmity that was further reported to restrict, to some or to a great extent, daily activities such as paid work or housework. Common mental disorders were measured by a 12 -item version of the General Health Questionnaire which is well-validated and indicates mainly non-psychotic, context-free affective mental ill-health, but more severe mental disorders as well. Following recommendations, those with $\geq 3$ out of the 12 symptoms were classified as having common mental disorders $(30,31)$.

\section{Statistical analysis}

First, prevalence data for workplace bullying and sleep problems were computed (table 1). Next, logistic regression analysis was used to examine associations of workplace bullying with subsequent sleep problems. Adjustments were made for the following confounders: age (models 1-5), childhood bullying (model 2), educational level and working conditions (model 3), obesity and physical and mental health (model 4), and baseline sleep problems (model 5). Finally, model 6 was adjusted for all the covariates simultaneously (models $1-5$ ). Interactions between gender and workplace bullying were also examined in the pooled data but none were found. All the analyses were conducted using the SAS statistical program, version 9.2 (SAS Institute, Cary, NC, USA).
Table 1. Distribution of key study variables at baseline (20002002) and follow-up (2007)

\begin{tabular}{lcc}
\hline & $\begin{array}{c}\text { Women } \\
(\mathrm{N}=5399) \\
\%\end{array}$ & $\begin{array}{c}\text { Men } \\
(\mathrm{N}=1247) \\
\%\end{array}$ \\
\cline { 2 - 3 } & & \\
Reported bullying at workplace at baseline & & 71 \\
No & 65 & 71 \\
Earlier, in this or another workplace & 19 & 13 \\
Yes, currently & 5 & 5 \\
I do not know & 11 & 11 \\
Observing workplace bullying at baseline & & \\
No & 36 & 43 \\
Sometimes & 51 & 44 \\
Frequently & 9 & 7 \\
I do not know & 5 & 5 \\
Sleep problems at baseline & 21 & 17 \\
Sleep problems at follow-up & 26 & 20 \\
\hline
\end{tabular}

\section{Results}

\section{Prevalence of workplace bullying and sleep problems}

At baseline, 5\% of women and men reported that they were bullied at their workplace, while reporting earlier bullying in the same or another workplace was more prevalent (table 1). For women and men, 9\% and 7\%, respectively, reported they had frequently observed bullying, whereas around half of both genders reported that they had at least sometimes observed bullying. Additionally, many participants could not say whether they had been bullied or had observed bullying. A fifth of women and slightly less men reported frequent sleep problems at baseline; sleep problems increased over the follow-up. Sleep problems were also persistent: $55 \%$ of men and $56 \%$ of women who reported frequent sleep problems at baseline also reported frequent sleep problems at followup (data not shown).

\section{Associations of workplace bullying with sleep problems}

Next, logistic regression analysis was used to examine the associations of workplace bullying at baseline with sleep problems at follow-up.

We first examined being bullied at baseline (table 2). Among women, bullying at baseline (OR 1.69, 95\% CI 1.30-2.20) and earlier bullying (OR 1.47, 95\% CI 1.261.72) were associated with subsequent sleep problems at follow-up when adjusted for age only (table 2, model 1). Adjusting for childhood bullying had but minor effects on these associations (model 2). Adjustments for education as well as physical and psychosocial working conditions somewhat attenuated the associations (model 3). After adjustment for obesity, limiting long-standing illness, and common mental disorders (model 4), no 
association was found for reported baseline bullying, although a weak association between earlier bullying and sleep problems remained (model 4: OR 1.30, 95\% CI 1.10-1.52). After adjustment for baseline sleep problems only, earlier bullying remained weakly associated with sleep problems (model 5: OR 1.30, 95\% CI 1.10-1.53). However, the association attenuated after adjusting simultaneously for all covariates (model 6).

Among men, corresponding age-adjusted associations with sleep problems (table 2, model 1) were found for both reporting bullying at baseline (OR 3.17, 95\% CI 1.85-5.43) and earlier bullying (OR $1.58,95 \%$ CI 1.06-2.36). In contrast to women, adjusting for childhood bullying weakened the associations and only reported bullying at baseline was associated with subsequent sleep problems (model 2: OR 2.69, 95\% CI 1.55-4.67). The point estimate for earlier bullying, however, remained at a level similar to that of women. As among women, adjustments for education, physical, and psychosocial working conditions (model 3 ) had only minor effects on the associations for men, whereas adjustment for obesity, limiting long-standing illness, and common mental disorders most attenuated the association of reported bullying with sleep problems (model 4: OR 2.27, 95\% CI 1.30-3.97). Unlike among women, the association remained after adjustment for baseline sleep problems among men (model 5: OR $2.60,95 \%$ CI 1.43-4.72). As among women, the association attenuated and lost statistical significance after adjusting simultaneously for all covariates (model 6). The point estimate, however, remained relatively strong.
As a next step, we examined observing bullying (table 3). Among women, frequently observing bullying was associated with sleep problems at follow-up when adjusted for age (model 1: OR 2.00, 95\% CI 1.61-2.48). Adjustment for childhood bullying (model 2) had a minor effect on the association for frequently observing bullying. After adjusting for further covariates (models 3-4), the association attenuated but remained (model 4: OR 1.48, 95\% CI 1.18-1.86). Adjustment for baseline sleep problems again weakened the association, but frequently observing bullying remained associated with subsequent sleep problems (model 5: OR 1.55, 95\% CI 1.23-1.96). Finally, after adjusting simultaneously for all covariates, the association attenuated (model 6).

Among men, in accordance with women, frequently observing bullying was associated with subsequent sleep problems when adjusted for age (table 3, model 1: OR 2.04, 95\% CI 1.23-3.39). Adjustment for childhood bullying somewhat attenuated the association (model 2: OR 1.76, 95\% CI 1.05-2.95). After further adjustments (models 3-6), the association of observing bullying with sleep problems was further reduced. The estimate, however, remained at a level similar to that of women.

Additionally, control analyses were conducted excluding those bullied at follow-up (data not shown). The OR for sleep problems at follow-up among men who reported bullying at baseline was $2.96(95 \% \mathrm{CI}$ $1.67-5.25)$ in the age-adjusted model and $1.59(95 \% \mathrm{CI}$ 1.20-2.11) among women, when those who were also bullied at follow-up were excluded. The correspond-

Table 2. Reporting bullying at workplace at baseline and subsequent sleep problems at follow-up. [0R=0dds ratios; $95 \% \mathrm{Cl}=95 \%$ confidence intervals]

\begin{tabular}{|c|c|c|c|c|c|c|c|c|c|c|c|c|}
\hline & \multicolumn{2}{|c|}{ Model $1^{\text {a }}$} & \multicolumn{2}{|c|}{ Model 2 b } & \multicolumn{2}{|c|}{ Model 3 c } & \multicolumn{2}{|c|}{ Model 4 d } & \multicolumn{2}{|c|}{ Model 5 e } & \multicolumn{2}{|c|}{ Model $6^{f}$} \\
\hline & $\mathrm{OR}$ & $95 \% \mathrm{Cl}$ & $\mathrm{OR}$ & $95 \% \mathrm{Cl}$ & OR & $95 \% \mathrm{Cl}$ & $\mathrm{OR}$ & $95 \% \mathrm{Cl}$ & $\mathrm{OR}$ & $95 \% \mathrm{Cl}$ & $\mathrm{OR}$ & $95 \% \mathrm{Cl}$ \\
\hline \multicolumn{13}{|l|}{ Women $(\mathrm{N}=5399)$} \\
\hline \multicolumn{13}{|l|}{$\begin{array}{l}\text { Perceived workplace } \\
\text { bullying }\end{array}$} \\
\hline No & 1.00 & & 1.00 & & 1.00 & & 1.00 & & 1.00 & & 1.00 & \\
\hline $\begin{array}{l}\text { Earlier, in this or } \\
\text { another workplace }\end{array}$ & 1.47 & $1.26-1.72$ & 1.43 & $1.22-1.67$ & 1.32 & $1.13-1.55$ & 1.30 & $1.11-1.52$ & 1.30 & $1.10-1.53$ & 1.14 & $0.96-1.36$ \\
\hline Yes, currently & 1.69 & $1.30-2.20$ & 1.63 & $1.25-2.13$ & 1.42 & $1.09-1.86$ & 1.23 & $0.94-1.62$ & 1.25 & $0.94-1.66$ & 0.99 & $0.74-1.33$ \\
\hline I do not know & 1.39 & $1.14-1.69$ & 1.36 & $1.12-1.65$ & 1.28 & $1.05-1.56$ & 1.22 & $1.00-1.48$ & 1.26 & $1.02-1.55$ & 1.13 & $0.91-1.40$ \\
\hline \multirow{2}{*}{\multicolumn{13}{|c|}{$\begin{array}{l}\text { Men }(\mathrm{N}=1247) \\
\text { Perceived workplace } \\
\text { bullying }\end{array}$}} \\
\hline & & & & & & & & & & & & \\
\hline No & 1.00 & & 1.00 & & 1.00 & & 1.00 & & 1.00 & & 1.00 & \\
\hline $\begin{array}{l}\text { Earlier, in this or } \\
\text { another workplace }\end{array}$ & 1.58 & $1.06-2.36$ & 1.39 & $0.92-2.09$ & 1.41 & $0.93-2.12$ & 1.42 & $0.94-2.14$ & 1.40 & $0.91-2.18$ & 1.20 & $0.76-1.91$ \\
\hline Yes, currently & 3.17 & $1.85-5.43$ & 2.69 & $1.55-4.67$ & 2.47 & $1.40-4.35$ & 2.27 & $1.30-3.97$ & 2.60 & $1.43-4.72$ & 1.81 & $0.94-3.48$ \\
\hline I do not know & 1.79 & $1.17-2.72$ & 1.69 & $1.11-2.59$ & 1.61 & $1.04-2.49$ & 1.55 & $1.01-2.39$ & 1.60 & $1.01-2.53$ & 1.45 & $0.91-2.33$ \\
\hline $\begin{array}{l}\text { adjusted for age. } \\
{ }^{\mathrm{b}} \text { Adjusted for age an } \\
{ }^{\mathrm{c}} \text { Adjusted for age, ed } \\
{ }^{\mathrm{d}} \text { Adjusted for age, ob } \\
{ }^{\text {Adjusted for age anc }}\end{array}$ & on, a & $\begin{array}{l}\text { Jullying. } \\
\text { working c } \\
\text { g long-star }\end{array}$ & illn & - and $c$ & & disorder & & & & & & \\
\hline
\end{tabular}


Table 3. Observing bullying at workplace at baseline and subsequent sleep problems at follow-up. [0R=0dds ratios; $95 \% \mathrm{Cl}=95 \%$ confidence intervals.]

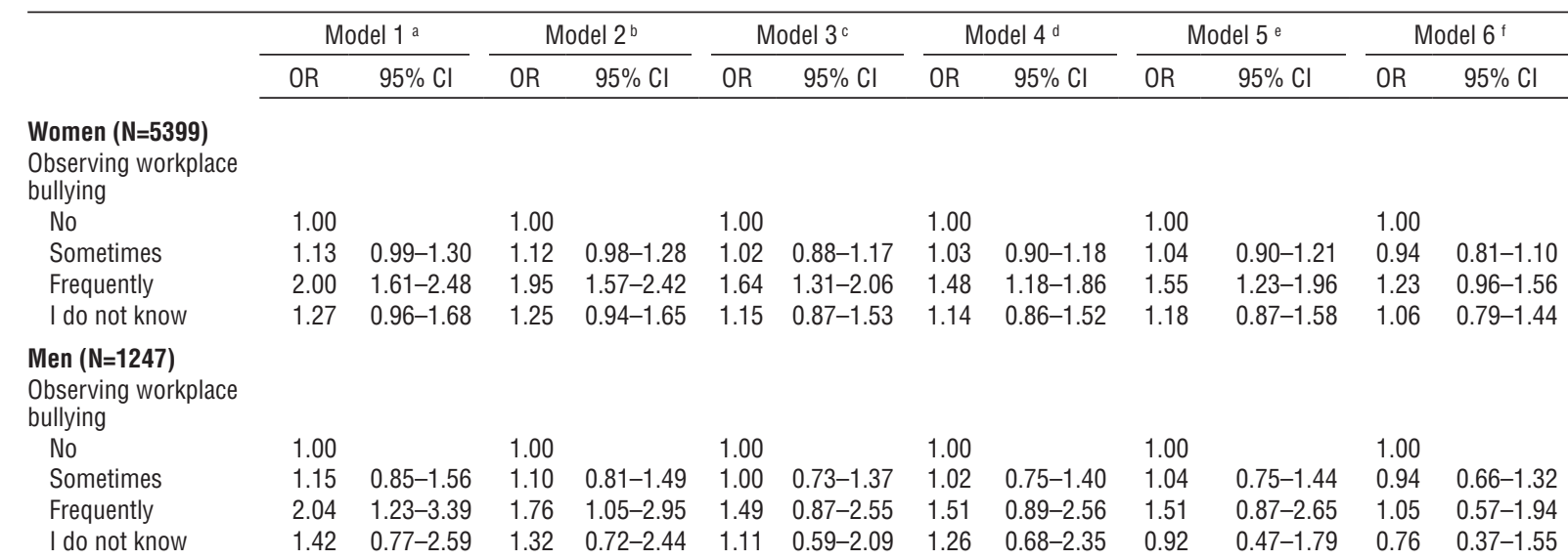

adjusted for age.

${ }^{\mathrm{b}}$ Adjusted for age and childhood bullying.

${ }^{c}$ Adjusted for age, education, and working conditions.

d Adjusted for age, obesity, limiting long-standing illness, and common mental disorders.

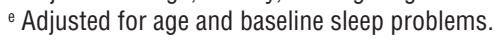

${ }^{\dagger}$ Adjusted for models 1-5 (full model)

ing OR for observing bullying were 1.75 (95\% CI $1.38-2.22)$ among women and 1.54 (95\% CI $0.87-2.70)$ among men when those who frequently observed bullying at follow-up were excluded.

\section{Discussion}

\section{Main findings}

This study sought to examine whether workplace bullying at baseline was associated with sleep problems at follow-up. Both women and men who reported they were bullied at baseline were more likely to report sleep problems at follow-up. After adjustments for baseline health and sleep problems, bullying at baseline remained associated with subsequent sleep problems among men and earlier bullying among women. Observing bullying was also associated with sleep problems at follow-up. However, after simultaneous adjustment for social factors and health, all of the associations between workplace bullying and sleep attenuated.

\section{Previous studies}

We lack previous studies about the consequences of reported or observing bullying on sleep problems using large prospective data, including a wide variety of occupations, for both men and women. Thus, comparisons to previous studies are limited. The associations between reported bullying at baseline and sleep problems at follow-up only partly confirmed results from a previous cross-sectional study (11). In our study, the associations of baseline bullying with sleep problems at follow-up attenuated after adjustments among women. However, in line with the previous study (11), current bullying remained associated with sleep problems among men, and earlier bullying among women. Measuring workplace bullying and sleep problems at one point in time only may be problematic since the direction of association cannot be judged. Longitudinal examination of sleep problems may also be problematic, as sleep problems tend to remain chronic and remissions are frequent (32). Thus, concerning participants who reported sleep problems already at baseline, the ceiling effect prevents any increase over the follow-up. In another study (19), workplace bullying was not associated with poor quality of sleep among nurses' aides during a threemonth follow-up. However, the study was restricted to one female-dominated occupational group with a short follow-up period as well as limited measurement of both bullying and sleep (single item extracted from a questionnaire). A long follow-up period could, nonetheless, affect the validity of our analysis, since many major life events over the 5-7-year follow-up time could also affect the emergence of sleep problems. Alternatively, the effects of bullying may be persistent as reporting earlier bullying was associated with sleep problems in a previous study as well (11). Thus, bullying is likely to have long-term consequences (ie, the contribution of bullying to sleep-related problems is likely to be evident also during a long follow-up time). This assumption is supported by associations of childhood bullying as well 
as earlier workplace bullying exposures with current sleep problems (data not shown). Thus, the effects of bullying are not just acute but also likely to be farreaching. However, cross-sectional associations tend to be stronger (11), and we acknowledge it is possible that we might have a stronger and a more consistent association among women and men with a shorter follow-up time. To be able to better exclude reverse causality and reporting bias, prospective studies with several measures of sleep and bullying are needed.

A couple of studies have examined the associations between workplace bullying and sleep-related problems such as self-reported use of sleep-induced drugs, tranquilizers, antidepressants, and sedatives $(9,33,34)$. These results further confirm that workplace bullying is likely to be important to various sleep-related problems. The effects of medication use on the present findings as well as the association of workplace bullying with subsequent use of psychotropic drugs warrants further examination.

The adjustment for covariates had varying effects on the studied associations. Sleep problems have been associated with sociodemographic and socioeconomic factors $(2,35,36)$, working conditions $(3,3,37)$, obesity (38-40), as well as mental and physical health $(41,42)$. Bullying is also connected to similar factors $(8,19,43)$. One might have assumed that these factors would contribute to the examined associations more consistently. Baseline sleep and health among women and childhood bullying among men attenuated, however, the associations between bullying and sleep problems. Some men may have been bullied already in school, which accounted for part of the effects of current bullying on sleep problems. A recent study also reported an association between childhood and workplace bullying, but only few of those who had been bullied at school ended up being bullied at work in adulthood (15). However, the link between past and present bullying was somewhat stronger among women than men in the previous study, whereas in our study childhood bullying did not contribute to the examined associations among women. Currently bullied men and women might be more likely to report childhood bullying as well. While the validity of retrospective reports may be limited, false negatives (forgetting or denying childhood bullying) are likely to be overrepresented more than false positives (falsely reporting bullying) (44). If that were the case in this study, the effects of adjustments on the associations would be conservative since the true prevalence of childhood bullying would be higher than that reported.

Negative affectivity could distort our findings together with the limited validity of retrospective questions. Accordingly, negative affectivity has been found to correlate with bullying and act as a potential mediator of the association between bullying and mental symptoms
(45). In addition, it is possible that bullying is a sensitive issue that is easily hidden or underreported. In line with this assumption, those who responded that they could not say whether they had been bullied or not were more likely to report sleep problems. If the true prevalence of currently bullied employees is higher than that reported, our estimates are again more likely to be conservative. Finally, as worry and stress are among the most common reasons for sleep problems among employed people, (4, 16-18), bullying may be a route leading to such worry or stress and thereby disturbed sleep. Although our questions about bullying did not specify who the bully was, any interpersonal conflicts with close colleagues and supervisors are likely to cause worry and stress and thereby sleep problems and mental ill-health among those who perceive such behavior (46). In all, bullying can be seen as an additional work-related stressor; associations with sleep problems are, however, modest and mostly attenuate when the effects of covariates are ruled out.

The reasons behind gender differences in the associations remained open for further scrutiny. Women and men were occupied in different jobs which could partly explain the difference. Due to the lower number of frequently bullied men with sleep problems, the result may also be an artifact. Alternatively, being bullied at the workplace is a stronger issue for men while women's sleep is less vulnerable to it. However, observing bullying could cause more stress to women than men due to empathy for and worry over colleagues and negative workplace climate resulting from bullying. As the effects of observing bullying also remained after the association was adjusted for reported bullying at baseline (data not shown), this further highlights the need to better understand the overall significance of bullying at the workplace with respect to health and well-being among employed women and men. However, several features of the work environment may differ between women and men and these differences may contribute to the differential associations as well. Thus, some of the effects of bullying on sleep problems may be linked to divergent working conditions and differences between work units and their members. These factors are also likely to explain some of the effects of bullying (9). As women and men are occupied in different jobs, varying social relations both between employees and between managers and supervisors may cause interpersonal conflict situations. Also job satisfaction and significance of work may differ between genders. Finally, we acknowledge that residual and unmeasured confounding are potential sources of bias in our exposure effect estimate (47). The estimate for earlier bullying was, however, of similar strength and direction among women and men and no interactions were found. Thus, the association concerning earlier bullying is likely to be similar between the genders. It is also possible that similar explanations for 
differences can be applied concerning earlier bullying as for current bullying (such as occupational structure, differences in work environmental exposures, members of the work unit). Also, lack of statistical power prevents from judging differences, as the confidence intervals were much wider among men than women.

\section{Limitations and strengths}

Some further limitations of this study need to be acknowledged. First, both the outcome, workplace bullying, and all the covariates were self-reported. Further studies having access to more objective and stronger measures of sleep problems, such as register data about medications and clinical diagnoses, are needed to confirm our findings.

Second, data about duration and intensity of bullying were unavailable and the proxy measures are likely to provide more conservative estimates to be confirmed with more extensive measures.

Third, since workplace bullying may be associated with depression and cardiovascular diseases (8), the complex associations between sleep and mental and physical health $(42,48,49)$ may further affect the interpretation of the present findings. To clarify the interrelationships and the effects of possible over-adjustment, this study examined the associations unadjusted and adjusted for mental health problems and other covariates in separate models in addition to testing the full model. Adjusting simultaneously for all of the covariates is complex as some of the apparent associations can disappear due to the fact that bullying is associated both with sleep and subsequent health but also sleep problems can affect health. Also overall, due to complex interrelationships between the covariates as well as sleep and bullying, the associations attenuated after full adjustment. In other words, in the full model, the possibility of overadjustment cannot be ruled out. In any case the full model is difficult to interpret. Thus, the models $1-5$ show the effects of separate adjustments in order to judge better the effects of each group of covariates on the studied association and the validity of the association between workplace bullying and sleep problems. Nevertheless, it is possible that social and work environmental factors as well as mental and physical health status account for most of the association between bullying on sleep, but further research is warranted.

Fourth, the questionnaire developed to examine sleep problems in clinical research has been validated among air traffic controllers and patients recovering from cardiac surgery only (25). However, it has been used in other previous epidemiological studies $(50,51)$, and the items are similar to the current insomnia criteria in the DSM-IV-TR (52) except that effects on daytime functioning were not asked. This is unlikely to distort our findings as we focused on the causes and not the consequences of sleep problems. Our cut-off point also reflects DSM-IV criteria (52) for insomnia although the response alternatives did not allow exactly similar categorization. Furthermore, in our and other previous studies, similar cut-off points have been used. However, direct comparisons may not be warranted due to somewhat varying measures of sleep $(35,50,51,53-55)$. We additionally conducted control analyses with a less severe cut-off point (ie, sleep problems occurring once a week on average). The results were largely similar and workplace bullying remained associated with sleep problems among women and men (data not shown). Data about childhood sleep problems were unavailable for the present study, which is a limitation as sleep problems may originate from childhood and persist over the lifetime (56).

Fifth, to minimize reporting bias and reverse causation, those bullied at follow-up were excluded. As the results largely remained, reporting bias and possibility for reverse causation are likely minor. Data about follow-up bullying was, however, only available for those continuously employed (over $70 \%$ of the baseline population).

Finally, the response rate of $67 \%$ at baseline in our study may also undermine the validity of the findings. However, at follow-up, the response rate was $83 \%$. Nonetheless, it is possible that those with the most severe sleep problems and/or bullying history had already exited the workforce. Alternatively, it is possible that only the employees most persistent to the adverse effects of bullying have remained in their jobs. Similar selection processes might concern sleep problems as well.

The strengths of this study include access to large and prospective data. In addition, sleep problems were identically measured both at baseline and follow-up. Thus, the associations of workplace bullying and subsequent sleep problems could be studied in a longitudinal design. Finally, we were able to include a variety of key social, work- and health-related determinants of sleep and bullying as covariates and retrospective childhood bullying to examine the effect of past exposures on the associations.

\section{Concluding remarks}

This study suggests that workplace bullying has associations with subsequent sleep problems but the associations differ by gender. Also earlier bullying is likely to have long-lasting effects on sleep. However, the associations attenuated after factors related to the social environment, work, and health were taken into account. To add to our understanding of the consequences of bullying and confirm these findings, workplace bullying needs to be examined in various occupational populations. 


\section{Acknowledgements}

The Helsinki Health Study is supported by grants from the Academy of Finland (grant umbers 1129225, 1121748, and 1135630), and the Finnish Work Environment Fund (grant numbers 107187 and 107281). Tea Lallukka is supported by the Academy of Finland (grant number133434), the Yrjö Jahnsson Foundation (grant number 4701380), and the Finnish Cultural Foundation (grant number 4701750). The authors also thank the City of Helsinki.

\section{References}

1. Ohayon MM. Epidemiology of insomnia: what we know and what we still need to learn. Sleep Med Rev. 2002;6:97-111. doi:10.1053/smrv.2002.0186.

2. Metlaine A, Leger D, Choudat D. Socioeconomic impact of insomnia in working populations. Ind Health. 2005;43:11-19. doi:10.2486/indhealth.43.11.

3. Lallukka T, Rahkonen O, Lahelma E, Arber S. Sleep complaints in middle-aged women and men: the contribution of working conditions and work-family conflicts. J Sleep Res. 2010;19:466-477. doi:10.1111/j.1365-2869.2010.00821.x.

4. Linton SJ. Does work stress predict insomnia? A prospective study. Br J Health Psychol. 2004;9:127-136. doi:10.1348/135910704773891005.

5. Einarsen S. The nature and causes of bullying at work. Int J Manpower. 1999;20:16-27. doi:10.1108/0143772991026858.

6. Einarsen S, Raknes BI, Mathiesen SB, Hellesøy OH. In Mobbing Og Harde Personkonflikter (Bullying and Harsh Personalized Conflict). Bergen: Sigma Forlag; 1994. p20.

7. Notelaers G, Einarsen S, de Witte H, Vermunt JK. Measuring exposure to bullying at work: The validity and advantages of the latent class cluster approach. Work \& Stress. 2006;20:288301. doi:10.1080/02678370601071594.

8. Kivimäki M, Virtanen M, Vartia M, Elovainio M, Vahtera J, Keltikangas-Järvinen L. Workplace bullying and the risk of cardiovascular disease and depression. Occup Environ Med. 2003;60:779-783. doi:10.1136/oem.60.10.779.

9. Vartia MA. Consequences of workplace bullying with respect to the well-being of its targets and the observers of bullying. Scand J Work Environ Health. 2001;27:63-69.

10. Kivimäki M, Elovainio M, Vahtera J. Workplace bullying and sickness absence in hospital staff. Occup Environ Med. 2000;57:656-660. doi:10.1136/oem.57.10.656.

11. Niedhammer I, David S, Degioanni S, Drummond A, Philip P, Acquarone D, et al. Workplace bullying and sleep disturbances: findings from a large scale cross-sectional survey in the French working population. Sleep. 2009;32:1211-1219.

12. McAvoy BR, Murtagh J. Workplace bullying. The silent epidemic. BMJ. 2003;776-777. doi:10.1136/bmj.326.7393.776.

13. Einarsen S, Hoel F, Zapf D, Cooper C (editors). Bullying and emotional abuse in the workplace. International perspectives in research and practice. London \& New York: Taylor \& Francis; 2003.

14. Sansone RA, Sansone LA. Bully victims: psychological and somatic aftermaths. Psychiatry (Edgmont). 2008;5:62-64.

15. Smith PK, Singer M, Hoel H, Cooper CL. Victimization in the school and the workplace: are there any links? Br J Psychol. 2003;94:175-188. doi:10.1348/000712603321661868.

16. Hall M, Buysse DJ, Nofzinger EA, Reynolds CF,3rd, Thompson W, Mazumdar S, et al. Financial strain is a significant correlate of sleep continuity disturbances in late-life. Biol Psychol. 2008;77:217-222. doi:10.1016/j.biopsycho.2007.10.012.

17. Shigemi J, Mino Y, Tsuda T. Stability of Factor Structure and Correlation with Perceived Job Stress in General Health Questionnaire. A Three-wave Survey over One Year in Japanese Workers. J Occup Health. 2000;42:284. doi:10.1539/joh.42.284.

18. Spiegel K, Knutson K, Leproult R, Tasali E, Van Cauter E. Sleep loss: a novel risk factor for insulin resistance and Type 2 diabetes. J Appl Physiol. 2005;99:2008-2019. doi:10.1152/ japplphysiol.00660.2005.

19. Eriksen W, Bjorvatn B, Bruusgaard D, Knardahl S. Work factors as predictors of poor sleep in nurses' aides. Int Arch Occup Environ Health. 2008;81:301-310. doi:10.1007/ s00420-007-0214-z.

20. Jiménez BM, MuñozAR, Vergel AIS, Carvajal RR. El efecto del acoso psicológico en el insomnio: el papel del distanciamiento psicológico y la rumiación [The effect of workplace byllying on insomnia: The role of psychological detachment and rumination]. Psicothema. 2008;20:760-765.

21. Lahelma E, Martikainen P, Rahkonen O, Roos E, Saastamoinen P. Occupational class inequalities across key domains of health: Results from the Helsinki Health Study. Eur J Public Health. 2005;15:504-510. doi:10.1093/eurpub/cki022.

22. Laaksonen M, Aittomäki A, Lallukka T, Rahkonen O, Saastamoinen P, Silventoinen K, et al. Register-based study among employees showed small nonparticipation bias in health surveys and check-ups. J Clin Epidemiol. 2008;61:900906. doi:10.1016/j.jclinepi.2007.09.010.

23. Martikainen P, Laaksonen M, Piha K, Lallukka T. Does survey non-response bias the association between occupational social class and health? Scand J Public Health. 2007;35:212-215. doi:10.1080/14034940600996563.

24. Hansen AM, Hogh A, Persson R, Karlson B, Garde AH, Orbaek P. Bullying at work, health outcomes, and physiological stress response. J Psychosom Res. 2006;60:63-72. doi:10.1016/j. jpsychores.2005.06.078.

25. Jenkins CD, Stanton BA, Niemcryk SJ, Rose RM. A scale for the estimation of sleep problems in clinical research. J Clin Epidemiol. 1988;41:313-321. doi:10.1016/0895-4356(88)90138-2.

26. Piirainen T, Hirvonen M, Elo A, Huuhtanen P, Kandolin I, Kauppinen K, et al. Työ ja terveys -haastattelututkimus 2003. Taulukkoraportti [The work and health interview study 2003. Basic report]. Helsinki: The Finnish Institute of Occupational Health (Työterveyslaitos); 2003.

27. Laaksonen M, Rahkonen O, Martikainen P, Lahelma E. 
Associations of psychosocial working conditions with selfrated general health and mental health among municipal employees. Int Arch Occup Environ Health. 2006;79:205-212. doi:10.1007/s00420-005-0054-7.

28. Karasek RA. Job Content Questionnaire and User's Guide. Lowell, MA. Department of Work Environment, University of Massachusetts; 1985.

29. Karasek R, Baker D, Marxer F, Ahlbom A, Theorell T. Job decision latitude, job demands, and cardio-vascular disease: a prospective study of Swedish men. Am J Public Health. 1981;71:694-705. doi:10.2105/AJPH.71.7.694.

30. Goldberg DP. The detection of psychiatric illness by questionnaire. Oxford: Oxford University Press; 1972.

31. Goldberg DP, Gater R, Sartorius N, Ustun TB, Piccinelli M, Gureje O, et al. The validity of two versions of the GHQ in the WHO study of mental illness in general health care. Psychol Med. 1997;27:191-197. doi:10.1017/S0033291796004242.

32. Morin CM, Belanger L, LeBlanc M, Ivers H, Savard J, Espie $\mathrm{CA}$, et al. The natural history of insomnia: a population-based 3-year longitudinal study. Arch Intern Med. 2009;169:447453. doi:10.1001/archinternmed.2008.610.

33. Appelberg K, Romanov K, Honkasalo ML, Koskenvuo M. The use of tranquilizers, hypnotics and analgesics among 18,592 Finnish adults: associations with recent interpersonal conflicts at work or with a spouse. J Clin Epidemiol. 1993;46:13151322. doi:10.1016/0895-4356(93)90100-F.

34. Richman JA, Rospenda KM, Nawyn SJ, Flaherty JA, Fendrich $\mathrm{M}$, Drum ML, et al. Sexual harassment and generalized workplace abuse among university employees: prevalence and mental health correlates. Am J Public Health. 1999;89:358 363. doi:10.2105/AJPH.89.3.358.

35. Arber S, Bote M, Meadows R. Gender and socio-economic patterning of self-reported sleep problems in Britain. Soc Sci Med. 2009;68:281-289. doi:10.1016/j.socscimed.2008.10.016.

36. Lallukka T, Arber S, Rahkonen O, Lahelma E. Complaints of insomnia among midlife employed people - the contribution of childhood and present socioeconomic circumstances. Sleep Med. 2010;11(9):828-836. doi:10.1016/j.sleep.2010.04.011.

37. Jansson M, Linton SJ. Psychosocial work stressors in the development and maintenance of insomnia: a prospective study. J Occup Health Psychol. 2006;11:241-248. doi:10.1037/1076-8998.11.3.241.

38. Fogelholm M, Kronholm E, Kukkonen-Harjula K, Partonen T, Partinen M, Härmä M. Sleep-related disturbances and physical inactivity are independently associated with obesity in adults. Int J Obes. 2007;31:1713-1721.doi:10.1038/sj.ijo.0803663.

39. Strine TW, Chapman DP. Associations of frequent sleep insufficiency with health-related quality of life and health behaviors. Sleep Med. 2005;6:23-27. doi:10.1016/j. sleep.2004.06.003.

40. Lyytikäinen P, Lallukka T, Lahelma E, Rahkonen O. Sleep problems and major weight gain: a follow-up study. Int J Obes (Lond). 2010 Jun 8. [Epub ahead of print].

41. Sivertsen B, Krokstad S, Overland S, Mykletun A. The epidemiology of insomnia: associations with physical and mental health. The HUNT-2 study. J Psychosom Res. 2009;67:109-116. doi:10.1016/j.jpsychores.2009.05.001

42. Morawetz M. Insomnia and Depression: Which Comes First? Sleep Research Online. 2003;5:77-81.

43. Ortega A, Hogh A, Pejtersen JH, Feveile H, Olsen O. Prevalence of workplace bullying and risk groups: a representative population study. Int Arch Occup Environ Health. 2009;82:417-426. doi:10.1007/s00420-008-0339-8.

44. Hardt J, Rutter M. Validity of adult retrospective reports of adverse childhood experiences: review of the evidence. J Child Psychol Psychiatry. 2004;45:260-273. doi:10.1111/j.14697610.2004.00218.x.

45. Mikkelsen EG, Einarsen S. Relationships between exposure to bullying at work and psychological and psychosomatic health complaints: the role of state negative affectivity and generalized self-efficacy. Scand J Psychol. 2002;43:397-405. doi:10.1111/1467-9450.00307.

46. Romanov K, Appelberg K, Honkasalo ML, Koskenvuo M. Recent interpersonal conflict at work and psychiatric morbidity: a prospective study of 15,530 employees aged 24-64. J Psychosom Res. 1996;40:169-176. doi:10.1016/0022-3999(95)00577-3.

47. Fewell Z, Davey Smith G, Sterne JA. The impact of residual and unmeasured confounding in epidemiologic studies: a simulation study. Am J Epidemiol. 2007;166:646-655. doi:10.1093/aje/kwm165.

48. Roth T. Comorbid insomnia: current directions and future challenges. Am J Manag Care. 2009;15 Suppl:S6-13.

49. Harvey A. Insomnia: symptom or diagnosis? Clin Psychol Rev. 2001;21:1037-1059. doi:10.1016/S0272-7358(00)00083-0.

50. Jerlock M, Gaston-Johansson F, Kjellgren KI, Welin C. Coping strategies, stress, physical activity and sleep in patients with unexplained chest pain. BMC Nurs. 2006;5:1-10. doi:10.1186/1472-6955-5-7.

51. Vahtera J, Pentti J, Helenius H, Kivimäki M. Sleep disturbances as a predictor of long-term increase in sickness absence among employees after family death or illness. Sleep. 2006;29:673-682.

52. American Psychiatric Association. Diagnostic and Statistical Manual of Mental Disorders. 4th edition text revision. Washington, DC: American Psychiatric Association; 2000.

53. Sivertsen B, Øverland S, Bjorvatn B, Mæland JG, Mykletun A. Does insomnia predict sick leave? The Hordaland Health Study. J Psychosom Res. 2009;66:67-74.

54. Sivertsen B, Øverland S, Pallesen S, Bjorvatn B, Nordhus $\mathrm{IH}$, Mæland JG, et al. Insomnia and long sleep duration are risk factors for later work disability. The Hordaland Health Study. J Sleep Res. 2009;18:122-128. doi:10.1111/j.13652869.2008.00697.x.

55. Salo P, Oksanen T, Sivertsen B, Hall M, Pentti J, Virtanen M, et al. Sleep disturbances as a predictor of cause-specific work disability and delayed return to work. Sleep. 2010 Oct 1;33(10):1323-31.

56. Dregan A, Armstrong D. Adolescence Sleep Disturbances as Predictors of Adulthood Sleep Disturbances-A Cohort Study. J Adolesc Health. 2010;46:482-487. doi:10.1016/j. jadohealth.2009.11.197.

Received for publication: 17 August 2010 